\title{
PERLINDUNGAN HUKUM HAK ASASI MANUSIA INTERNASIONAL TERHADAP IMIGRAN SURIAH
}

\author{
Mentari Jastisia \\ Universitas Wiralodra \\ Email: mjastisia@gmail.com,
}

\begin{abstract}
Immigrants are people who have fled from their country to other countries where they can be referred to as refugees or asylum seekers. There are legal instruments that regulate and provide protection for them. Arrangements for asylum seekers are contained in the 1967 Declaration of Territorial Asylum, State practice, humanitarian issues, Declaration of Human Rights (UDHR). Meanwhile, the arrangements for refugees are contained in the Convention Relating to the Status of Refugees 1951, Protocol relating to the status of Refugees 1967, International Covenant on Civil and Political Rights (ICCPR). This papers uses a normative juridical method. This juridical approach is because this research analyzes existing legal aspects, and is normative because this research focuses more on the analysis of existing laws and regulations and other regulations, using secondary data, namely scientific references or other scientific writings as study material that can support the completeness of this scientific papers. Regarding legal protection for Syrian immigrants, the same applies to immigrants from other state as regulated in the arrangements that have been regulated. Countries in the European Union implement international human rights law protections for Syrian immigrants residing in European Union countries consistently as mandated in the European Convention on Human Rights, Convention applying the Schengen Agreement dated June 14, 1985, Lisbon treaty, Dublin II Regulation (Council Regulation (EC) 343/2003) 2003. The indication is that there are several countries in the European Union such as Greece, Hungary which refuse and do not want to take more responsibility for their obligations as a State related to the provisions of international human rights law to provide protection for Syrian immigrants in Europe.
\end{abstract}

\section{Keywords: Legal Protection, Human Rights, Syrian Immigrants}

\section{PENDAHULUAN}

Idealnya keberadaan Perserikatan Bangsa-Bangsa (PBB) sebagai suatu organisasi Negara-negara tingkat dunia dapat mewujudkan harapan bagi masyarakat internasional di bidang perdamaian dan keamanan internasional. Konsekwensinya, pertahanan perdamaian dan keamanan dunia masih merupakan sebuah harapan Negara-negara dunia. Berjuta-juta penduduk terus menderita karena perang, tirani, fanatisme, ketidakadilan, ekonomis, 
keadilan sosial, politik serta persebaran senjata- senjata pemusnah missal masih tertimbun di berbagai tempat dunia ${ }^{1}$.

Kondisi tersebut diatas, tentunya memberikan gambaran bahwa dibanyak Negara masih banyak terjadi pelanggaran Hak Asasi Manusia (HAM) yang meresahkan umat manusia didunia dan sudah semestinya terehadap kondisi demikian mendapat perhatian prioritas dari PBB melalui komisi yang dibentuknya. Meskipun keberadaan Deklarasi Universal Hak Asasi Manusia tersebut bukan merupakan bentuk ketentuan yang mengikat (binding), tetapi setidak-tidaknya telah menjadi landasan bagi pembentukan norma-norma HAM internasional yang di implementasikan dalam berbagai format perjanjian internasional yang secara normatif mengikat Negara-negara sebagai pihak yang mengikatkan diri didalamnya ${ }^{2}$.

Konvensi tahun 1951 berikut protokolnya tahun 1967 secara substansial melidungi HAM pada pengungsi. Dengan demikian Konvensi tersebut dikategorikan sebagai jenis-jenis HAM yang perlu dilindungi, khususnya bagi pengungsi. Hukum HAM dibagi dalam tiga keadaan, yaitu: ${ }^{3}$ Pertama, hukum HAM umum yang berlaku bagi semua orang dalam keadaan normal. Kedua, hukum HAM yang diberlakukan dalam situasi perang dikenal dengan hukum humaniter. Ketiga, hukum HAM yang khusus diterapkan kepada pengungsi (dikenal dengan hukum pengungsi). Hukum HAM ini diterapkan kepada pengungsi karena berada di luar Negaranya serta tidak ada yang melindungi.

Bermula dari kota selatan Deraa, pada bulan Maret 2011 penduduk setempat berkumpul melakukan unjuk rasa yang menuntut agar pasukan keamanan Suriah membebaskan 14 mahasiswa yang telah ditangkap karena dituduh telah merongrong stabilitas keamanan Suriah dengan cara melakukan provokasi melalui tulisan di dinding, slogan terkenal dari pemberontakan rakyat di Tunisia dan Mesir: "Orang-orang ingin kejatuhan rezim". Para demonstran juga menyerukan demokrasi dan kebebasan yang lebih besar ${ }^{4}$. Selama terjadi pergolakan peperangan saudara di Suriah, $\mathrm{PBB}^{5}$ mencatat

1 PBB, Pengetahuan Dasar Mengenai Perserikatan Bangsa-Bangsa, (Jakarta: Kantor Penerangan PBB (UNIC), hlm. 33.

2 Rita Maran, Perkembangan Hak Asasi Manusia dalam Politik Internasional, artikel dimuat dalam Jurnal Demokrasi dan HAM, Vol. 1 No. 3, Maret-Juni 2001, The Habibie Center, hlm. 159.

3 Eny Haryono dalam Wagiman, Hukum Pengungsi Internasional, Sinar Grafika, Jakarta, 2012, hlm. 32.

4 Syria. International Monetary Fund. Diunduh pada tanggal 14 Oktober 2015. 
lebih dari 220.000 warga Suriah tewas, jumlah tersebut tidak termasuk korban tewas dari pihak pemerintah yang berkuasa di bawah kendali Presiden Bashar Al-Assad.

Negara-negara di Uni Eropa dijadikan salah satu Negara yang dituju oleh pengungsi Suriah, karena selama konflik politik dan peperangan antar kelompok yang bertikai tidak ada daerah yang disepakati sebagai safe zone dan non-fly zone oleh pihak yang saling bertikai. Kebijakan open door policy kepada para pengungsi Suriah oleh Erdogan membuat banyak pengungsi lari ke Turki. Turki juga dipilih karena dari Turki para pengungsi Suriah bisa berpeluang 'menerobos' ke Eropa. Di Eropa-lah, para pengungsi ini berharap mendapatkan status asylum ${ }^{6}$.

Melihat latar belakang tersebut upaya masyarakat internasional sudah banyak seperti Liga Bangsa-Bangsa yang membentuk Komisaris Tinggi Liga Bangsa-Bangsa untuk menetapkan status hukum dan memastikan diberikannya perlindungan internasional untuk para pengungsi. Upaya ke arah pembentukan instrumen internasional sebagaimana telah dirintis PBB baru bisa dilanjutkan pasca Perang Dunia Kedua ${ }^{7}$. Terdapat instrumen hukum yang mengatur dan memberikan perlindungan terhadap mereka. Pengaturan bagi asylum seeker terdapat pada Declaration of Territorial Asylum 1967, praktek Negara, persoalan kemanusian, Declaration of Human Rights (UDHR). Sedangkan pengaturan bagi pengungsi terdapat pada Convention Relating to the Status of Refugees 1951, Protocol relating to the status of Refugees 1967, International Covenant on Civil and Political Rights (ICCPR).Pengaturan mengenai pengungsi atau asylum seeker sudah di atur di Eropa juga, tetapi masih ada beberapa Negara di Eropa yang tidak mau menerima tanggung jawab lebih terkait hal tersebut.

\section{IDENTIFIKASI MASALAH}

Penulis berpandangan bahwa topik yang dipaparkan diatas, cukup menarik untuk dilakukan penelitian dan dianalisa dalam bentuk karya tulis ilmiah dengan membatasi identifikasi masalah:

1. Untuk mengetahui perlindungan hukum HAM internasional terhadap imigran Suriah.

\footnotetext{
5 Adirini Pujayanti, Isu Pencari Suaka dan Kebijakan Uni Eropa, Jurnal Vol. VII, No.17/1/P3DI/ September/2015.

6 Syria. International Monetary Fund. Diunduh pada tanggal 14 Oktober 2015.

7 Wagiman, S.Fil, Hukum Pengungsi Internasional, Jakarta: Sinar Grafika, 2012, hlm. 32.
} 
2. Untuk mengetahui implementasi perlindungan hukum terhadap imigran Suriah di Eropa.

\section{METODE}

Pokok bahasan dalam tulisan ini berhubungan dengan perlindungan hukum HAM internasional terhadap imigran Suriah. Oleh karena itu, proses penulisan karya ilimiah ini terarah, penulis menggunakan teori hukum internasional dan hak asasi manusia (HAM). Dalam pandangan Mochtar Kusumaatmadja, bahwa hukum internasional adalah seluruh kaidah dan asas yang mengatur hubungan yang melintasi batas-batas antarnegara. Hubungan yang melintasi batas-batas nasional Negara-negara (hubungan internasional) tersebut dapat terjadi baik hubungan yang diadakan Negara dengan Negara maupun Negara dengan subjek hukum internasional lainnya yang bukan Negara ${ }^{8}$.

Dalam konteks masyarakat internasional, terdapat pengakuan bahwa setiap Negara mempunyai hak eksklusif dalam batas wilayah Negaranya tanpa ada keterikatan atau pembatasan dari hukum iternasional ${ }^{9}$. Hak dasar suatu Negara mencakup salah satunya adalah yurisdiksi territorial ${ }^{10}$. Yurisdiksi merupakan kewenangan untuk melaksaanakan ketentuan hukum nasional suatu Negara berdaulat dan ini merupakan sebagian implementasi kedaulatan Negara sebagai yurisdiksi Negara dalam batas-batas wilayahnya akan tetap melekat pada Negara berdaulat ${ }^{11}$.

Sebagai subjek hukum internasional, Negara memiliki kedaulatan yang diakui oleh hukum internasional. Terkait imigran, yaitu orang yang melarikan diri dari Negaranya ke Negara lain, sampai sekarang belum ada pengaturan yang jelas dan tegas. Imigran yang melarikan diri ke luar negeri dapat disebut asylum seeker atau pengungsi. Masuknya seseorang ke dalam suatu teritorial tertentu, dengan asumsi ia mencari suaka. Suaka adalah penganugrahan perlindungan dalam wilayah suatu Negara kepada orangorang dari Negara lain yang datang ke Negara bersangkutan karena menghindari pengejaran atau bahaya besar ${ }^{12}$.

\footnotetext{
8 Mochtar Kusumaatmadja, Pengantar Hukum Internasional, Bandung, 2003, hlm. 2.

9 Imam Santoso, Perspektif Imigrasi Dalam Nation Convention Against Transnational Organizet Crime, Perum Percetakan Negara RI, Jakarta, hlm.42.

${ }^{10}$ Wagiman. Op. Cit., hlm. 18.

11 Yudha Bhakti dalam Wagiman, Ibid.

${ }^{12}$ Ajat Sudrajat Havid, Pengungsi dalam Kerangka Kebijakan Keimigrasian Kini dan yang Akan Datang. Lihat, Protecting Refugee, A field Guide for NGO's tanpa tahun, hlm. 125.
} 
Konvensi Tentang Pengungsi 1951 juga memberikan definisi mengenai pengungsi. Konvensi ini memuat definisi pengungsi yang sangat umum dalam Pasal 1A ayat (2) Convention Relating to the Status of Refugees $1951^{13}$. Adapun Protokol mengenai Pengungsi 1967. Dalam Pasal 1 ayat (2) protocol ini, pengertian pengungsi dalam konvensi 1951 diperluas. Instrumen yang terkait dengan pengungsi dalam kawasan Eropa antara lain ${ }^{14}$ Agreement of the Abolition of Visas for Refugees, European Agreement on Transfer of Responsibility for Refugess, dan Reccomendation on the Protection of Persons not Formally Recognized as Refugees Under 1951 Convention.

Membicarakan hukum pengungsi internasional harus dilengkapi juga membicarakan hukum migrasi internasional. Migrasi adalah perpindahan penduduk dengan tujuan untuk menetap dari suatu tempat ke tempat lain melewati batas administratif (migrasi internal) atau batas politik / Negara (migrasi internasional) ${ }^{15}$.

Terkait hal di atas beberapa prinsip telah mencakup hak-hak asasi manusia internasional. Hal yang sangat fundamental dari hak asasi manusia pada jaman sekarang adalah ide yang meletakkan semua orang terlahir bebas dan memiliki kesetaraan dalam hak asasi manusia. Kemudian yang tidak kalah penting adalah Menurut hukum hak asasi manusia internasional, suatu Negara tidak boleh secara sengaja mengabaikan hak-hak dan kebebasan-kebebasan ${ }^{16}$.

Banyak Negara-negara yang tidak mau mengikatkan dirinya terhadap konvensi tersebut dengan berbagai alasan dan pandangannya masing-masing, namun di samping itu semua Negara, yang pada prinsipnya dibentuk berdasarkan kontrak dan sebagai personalitas internasional, tanpa terkecuali mempunyai kewajiban yang sama di dalam perlindungan dan penegakan hak asasi manusia ${ }^{17}$. Masalah status pengungsi merupakan bagian dari hukum internasional, pengungsi adalah suatu status yang diakui oleh hukum internasional.

\footnotetext{
${ }^{13}$ Konvensi ini disepakati tanggal 25 Juli 1951 namun baru diberlakukan pada tanggal 22 April 1954. Konvensi ini disetujui pada Konferensi PBB tentang Pengungsi dan orang-orang Tanpa Kewarganegaraan yang diselenggarakan di Geneva. Konferensinya itu sendiri merupakan mandate dari Resolusi PBB Nomor 429 (V).

${ }^{14}$ Uni Eropa Bahas Kebijakan Mengenai Pengungsi, www.dw-world.de/dw/article/0,4131532,00.html. Diunduh pada tanggal 15 Januari 2016.

15 Pengertian dan Ruang Lingkup Mobilitas Penduduk, makalah dimuat dalam http://meetabied.wordpress .com/2010/01/14makalah-mobilitas-penduduk/

16 Rita Maran, Perkembangan Hak Asasi Manusia dalam Politik Internasional, artikel dimuat dalam Jurnal Demokrasi dan HAM, Vol. 1 No. 3, Maret-Juni 2001, The Habibie Center, hlm. 159.

${ }^{17}$ Eny Haryono, Permasalahan di Sekita Pengungsi, www.seputarkita.com. Diunduh pada tanggal 11 Januari 2016.
} 
Adapun UNHCR yang menjalankan prosedur Penentuan Status Pengungsi (RSD), yang dimulai dengan registrasi atau pendaftaran terhadap para pencari suaka. Setelah registrasi, UNHCR akan melakukan wawancara individual dengan masing masing pencari suaka, dengan didampingi seorang penerjemah yang kompeten. Proses ini melahirkan keputusan yang beralasan yang menentukan apakah permintaan status pengungi seseorang diterima atau ditolak dan memberikan masing - masing individu sebuah kesempatan (satu kali) untuk meminta banding apabila permohonannya ditolak $^{18}$.

\section{HASIL DAN PEMBAHASAN}

\section{A. Perlindungan hukum HAM Internasional terhadap imigran Suriah}

Masalah kemanusiaan yang dihadapi oleh para pengungsi Suriah ketika terpaksa keluar dari Negaranya dan masuk ke Negara orang lain merupakan masalah yang rumit dan kompleks sehingga tidak dapat dengan mudah saja dicari solusi terbaiknya. Awalnya imigran Suriah hanya ditempatkan di Negara-negara tetangga seperti Iran dan Libya namun kini mulai menyebar kewilayah Eropa terutama Jerman. Salah satu alasannya adalah untuk mendapatkan perlindungan dan menghilangkan pendengaran atas saudarasaudaranya yang sedang berada di medan perang. Akan tetapi, keinginan mereka untuk berada di Eropa tidak sepenuhnya mendapat tanggapan baik dari Negara-negara di benua tersebut. Dalam kondisi demikian, perlu ada perangkat hukum HAM internasional yang memproteksi para imigran pada umumnya. Hak Asasi Manusia (HAM) merupakan hal yang relatif baru. Sejak perjanjian Westpalia tahun 1648 sampai lahirnya Piagam Perserikatan bangsa-Bangsa (PBB) tahun 1945 belum menjadi agenda Internasional. Esensi hukum hak asasi manusia internasional mengatur kemanusiaan universal tanpa terikat atribut ruang dan waktu tertentu ${ }^{19}$.

Hukum internasional telah meletakan kewajiban dasar bagi tingkah laku Negara dalam melaksanakan perlindungan internasionalnya. Tindakan yang bertentangan dengannya akan melahirkan tanggung jawab internasional. Tangggung jawab internasioanal diartikan sebagai suatu perbuatan salah yang memiliki karakteristik

\footnotetext{
${ }^{18}$ United Nation High Commisioner for Refugees, 2003, Membantu Para Pengungsi, Terbitan Berkala UNHCR Tahun 2003.

${ }^{19}$ Agus Fadhillah, Pengantar Hukum Internasional dan Hukum Humaniter Internasional, Elsam. Jakarta, hlm. 6-7.
} 
internasional. Tanggung jawab demikian muncul manakala terdapat pelanggaran yang sungguh-sungguh terhadap hal-hal yang menyangkut perlindungan atas hak-hak asasi manusia, termasuk di dalamnya hak asasi pengungsi.

Terkait perlindungan pengungsi atau pencari suaka telah di atur oleh hukum HAM internasional seperti pada Convention Relating to the Status of Refugees 1951, Declaration of Territorial Asylum Seeker 1967, International Covenant on Civil and Political Rights (ICCPR), dan Universal Declaration of Human Rights (UDHR).

Berdasarkan ketentuan di atas maka hak untuk mendapat perlindungan suaka di Negara lain termasuk kelompok hak asasi yang harus diakui secara universal karena tiaptiap manusia memiliki hak inheren untuk hidup yang harus dilindungi oleh hukum. Serta telah di atur juga mengenai hak-hak dan kewajiban Negara peserta konvensi yang harus dilakukan kepada pengungsi tersebut. Oleh karena itu perlindungan hukum yang harus di berikan kepada imigran yang keluar dari Negaranya untuk mencari perlindungan di Negara lain dalam hal ini imigran Suriah haruslah di berlakukan hukum yang sama tentunya dengan menanggapi secara baik dari Negara-negara yang di datanginya dan tidak dapat di kembalikan ke Negara asalnya dimana keamanannya sedang terancam.

\section{B. Analisis Implementasi perlindungan hukum bagi Imigram Suriah di Eropa}

Konflik peperangan yang terjadi di Suriah menimbulkan ketidakpastian atas keselamatan masyarakatnya. Hal ini menyebabkan jutaan warga Negara Suriah harus rela merubah status mereka menjadi pengungsi dan mencari perlindungan baik di dalam negeri terlebih lagi ke luar negeri. Salah satu Negara yang menjadi penerima pengungsi Suriah adalah Uni Eropa. Uni Eropa adalah salah satu kawasan dunia yang paling stabil dari segi politik dan paling makmur. Negara-negara anggotanya mematuhi prinsip bahwa mereka harus menawarkan suaka bagi mereka yang lari akibat perang saudara atau tekanan politik. Dalam konflik ini terdapat kerjasama antara Uni Eropa dengan United Nations High Commisioner for Refugees (UNHCR) dalam upaya menangani pengungsi Suriah di Eropa.

Menurut UNHCR pada desember 2014 bahwa para pengungsi asal Suriah telah mendapatkan penawaran settlement diberbagai Negara di Eropa, Amerika hingga Australia dengan kuantitas yang berbeda-beda setiap Negara. Sebanyak 4 juta lebih penduduk suriah yang telah memutuskan untuk mengungsi ke Negara-negara belahan 
dunia lainnya dengan penyebaran telah menyentuh seluruh benua ${ }^{20}$. Menurut UNHCR "Resettlement" adalah penempatan baru tetap terutama pengungsi terluka, ke Negara ketiga yang mau menerima. Ini diharap memberi perlindungan penuh bagi pengungsi terkait dan membuka perspektif integrasi. UNHCR juga menyerukan redistribusi pengungsi yang merata di Uni Eropa dan juga telah menghimbau kepada pemerintah di Uni Eropa untuk memastikan bahwa mereka menangani situasi ini dengan sensitif dan mematuhi kewajiban internasional.

1. Dublin II Regulation yang mengatur tentang Suaka Uni Eropa tidak dapat Mengesampingkan Prinsip Non-Refoulement

Dublin II Regulation dibuat untuk menjadikan sirkulasi keluar masuknya pencari suaka maupun pengungsi dapat teratur, namun dalam kenyataannya ternyata ciri khas yang terdapat dalam peraturan Dublin Regulation adalah adanya pemindahan pencari suaka $^{21}$ yaitu Pasal 17 dan Pasal 18 Regulation yang kerap dilaksanakan dan kebanyakan pemindahan tersebut ditujukan ke Negara Uni Eropa yang meiliki keterbatasan sistem, penerimaan pencari suaka yang dapat mengakibatkan hak-hak mendasar pencari suaka terlanggar, dalam hal ini contohnya adalah Yunani.

Kesimpulan yang didapat adalah walaupun Negara-negara Uni Eropa telah secara sadar melaksanakan kewajiban dari primary legislation Uni Eropa, namun pelaksanaan secara teknis dikembalikan lagi ke hukum nasional Negara anggota Uni Eropa tersebut.

2. Prinsip Non-Refoulment sebagai Hukum Kebiasaan Internasional dalam Hukum Pengungsi Internasional

Konvensi tentang Pengungsi 1951 merupakan sebuah instrumen internasional yang lahir pada rezim penegakkan hak asasi manusia. Prinsip non-refoulement pada dasarnya berkaitan dengan prinsip perlindungan dalam hukum hak asasi manusia, utamanya dalam kaitannya dengan perlindungan individu dari tindakan- tindakan yang dapat dikategorikan sebagai penyiksaan dan atau penghukuman yang kasar dan merendahkan martabat dan tidak manusiawi. Prinsip yang paling mendasar bagi keseluruhan sistem hukum pengungsi internasional ini telah dilebagakan dalam Pasal 33 Konvensi tentang Pengungsi 1951. Dalam sistem hukum pengungsi internasional, keberadaan prinsip non-refoulement telah dilembagakan dalam berbagai instrumen

\footnotetext{
${ }^{20} \mathrm{Di}$ akses dari http://www.unhcr.org.

${ }^{21}$ Transfer of Asylum Seekers.
} 
hukum internasional yang berupa konvensi, deklarasi, maupun dalam hukum kebiasaan internasional. Makna utama dari prinsip non-refoulement adalah tidak boleh ada Negara yang mengembalikan atau mengirim pengungsi dan atau pencari suaka ke suatu wilayah tempat kehidupan dan keselamatan pengungsi atau pencari suaka tersebut benar-benar terancam.

\section{B. PENUTUP}

\section{A. Simpulan}

1. Imigran adalah orang yang melarikan diri dari Negaranya ke Negara lain di mana dapat disebut sebagai pengungsi atau asylum seeker. Terdapat instrumen hukum yang mengatur dan memberikan perlindungan terhadap mereka. Pengaturan bagi asylum seeker terdapat pada Declaration of Territorial Asylum 1967, praktek Negara, persoalan kemanusian, Declaration of Human Rights (UDHR). Sedangkan pengaturan bagi pengungsi terdapat pada Convention Relating to the Status of Refugees 1951, Protocol relating to the status of Refugees 1967, International Covenant on Civil and Political Rights (ICCPR).

2. Terkait dengan perlindungan hukum terhadap imigran Suriah berlaku sama terhadap imigran dari Negara lainnya sebagaimana diatur dalam pengaturan yang telah di atur tersebut. Negara-negara di Uni Eropa mengimplementasi perlindungan hukum HAM internasional terhadap imigran Suriah yang berada di Negara-negara Uni Eropa dengan konsisten sebagaimana di amanatkan dalam European Convention on Human Rights, Convention applying the Schengen Agreement tanggal 14 Juni 1985, Lisbon treaty, Dublin II Regulation (Council Regulation (EC) 343/2003) tahun 2003. Indikasinya ada beberapa Negara di Uni Eropa seperti Yunani, Hungaria yang menolak dan tidak mau mengambil tanggung jawab lebih terhadap kewajibannya selaku Negara yang terkait dengan ketentuan hukum HAM internasional untuk memberikan perlindungan terhadap imigran Suriah di Eropa.

\section{B. Saran}

1. Selayaknya jaminan perlindungan harus diberikan oleh semua negara dan tidak terbatas hanya bagi negara-negara yang memiliki hubungan persekutuan internasional untuk menjamin perlindungan kepada seluruh penduduk suatu 
negara, terlebih lagi bagi mereka para pengungsi yang membutuhkan perlindungan lahir dan batin akibat kerasnya kehidupan di negara sebelumnya.

2. Jaminan perlindungan tersebut, sebaiknya harus tetap diberikan meskipun suatu negara tidak memiliki pengaturan dalam memberikan perlindungan terhadap para pengungsi dari negara lain, setidaknya perlu dilakukan pandangan menyeluruh dari segi kemanusiaan.

\section{DAFTAR PUSTAKA}

\section{A. Buku :}

Achmad Romsan, dkk. Pengantar Hukum Pengungsi Internasional, Bandung: Sanic Offset. 2003.

Atik Krustiyati, "Penanganan Pengungsi di Indonesia" Tinjauan Aspek Hukum Internasional dan Nasional. Brilian Internasional. Surabaya. 2010.

Boer Mauna, Hukum Internasional : Pengertian, Peranan dan Fungsi dalam Era Dinamika Global, Edisi Kedua, Penerbit P.T. Alumni, Bandung, 2008.

Damos Dumoli Agusman, Hukum Perjanjian Internasional: Kajian Teori dan Praktik Indonesia, Cetakan Kesatu, PT Refika Aditama, Bandung, 2010.

Daniel Warner. The Refugee State and State Protection, dalam "Refugee Rights and Realities. Cambridge University Press. 1999.

Davidson. Hak Asasi Manusia: Sejarah, Teori, dan Praketk dalam Pergaulan Internasional. Jakarta: Pustaka Grafiti. 1994.

Dudung Indra Ariska, Yurisdiksi Asas Oportunitas dalam Sistem Peradilan Pidana Indonesia, deepublish, Yogyakarta, 2013.

Mochtar Kusumaatmadja dan Etty R. Agoes, Pengantar Hukum Internasional, P.T. Alumni, Bandung, 2003.

M Rudi Rizki, Pokok-Pokok Hukum Hak Asasi Manusia Internasional. Seri Bahan Bacaan Kursus HAM Tahun 2005, Lembaga Studi dan Advokasi Masyarakat, Jakarta, 2005. 
Soerjono Soekanto dan Sri Mamudji, Penelitian Hukum Normatif Suatu Tinjauan Singkat, Raja Grafindo, Jakarta, 2001

Sulaeman Hamid, Lembaga Suaka dalam Hukum Internasional, PT Raja Grafindo, Jakarta, 2002.

Wagiman, Hukum Pengungsi Internasional, Cet. 1, Sinar Grafika, Jakarta Timur, 2012. Walter Cairns, Introduction to European Union Law (2 $2^{\text {nd }}$ Edition), Cavendish Limited,

London. Sidney, 2002.

\section{B. Perundang-undangan}

1. Instrumen Hukum Internasional: United Nations Charter.

Universal Declaration of Human Rights (UDHR). Convention Relating to the Status of Refugees 1951.Declaration of Territorial Asylum 1967.

International Covenant on Civil and Political Rights (ICCPR).

European Contion on Human Rights. United Nation of Human.

2. Perjanjian Internasional Regional Uni Eropa

Dublin II Regulation (Council Regulation (EC) 343/2003) tahun 2003.

Council Directive 2003/9/EC of 27 January 2003 laying down minimum standards forthe reception of asylum seekers (OJ 2003 L 31, p. 18) tahun 2003.

Convention applying the Schengen Agreement tanggal 14 Juni 1985. Agreement of the Abolition of Visas for Refugees 1959.

European Agreement on Transfer of Responsibility for Refugess 1980.

Reccomendation on the Protection of Persons not Formally Recognized as RefugeesUnder 1951 Convention.

European Refugee Fund Regulation 2008.

Lisbon Treaty (TFEU, TEU dan CFR) tahun 2009. 